\title{
Orthodontists' and Orthodontic Residents' Education in Treating Underserved Patients: Effects on Professional Attitudes and Behavior
}

\author{
Brett R. Brown, D.D.S.; Marita Rohr Inglehart, Dr. phil. habil.
}

Abstract: The U.S. surgeon general's report on oral health in 2000 stressed the importance of providing dental care for underserved patient groups. Given that orthodontic treatment is less likely to be covered by dental plans than other procedures and is often considered an elective treatment, it is not surprising that access to orthodontic care is an especially severe problem for underserved patient groups. The purpose of this study was to explore the degree to which orthodontic residents and orthodontists perceived that their graduate orthodontic education had prepared them well to treat underserved patients and whether this education affected their professional attitudes and behavior concerning providing care for members of historically underserved patient groups. Survey data were collected from 135 residents in U.S. and Canadian graduate orthodontic programs and from 568 active members of the American Association of Orthodontists (AAO). While the majority of residents and orthodontists felt well prepared to treat patients from different ethnic/racial backgrounds (quality of clinical education: residents: 86.4 percent; orthodontists: 82.3 percent), considerably fewer respondents felt well prepared to treat patients on Medicaid (64.7 percent and 34.4 percent), pro bono cases (45.4 percent and 33.4 percent), patients with special needs ( 52.8 percent and 35 percent), patients with craniofacial anomalies (65.3 percent and 52.6 percent), and patients with developmental delays ( 45.5 percent and 30.5 percent). Perceptions of the quality of education correlated significantly with the professional attitudes and the actual/projected behavior concerning providing care for patients from these underserved patient groups. Given the lack of access to orthodontic care for patients from underserved patient groups, initiatives are needed to change this situation. These findings showed a clear relationship between how future orthodontists are educated about providing care for patients from underserved populations and their professional attitudes and behavioral intentions to provide care for individuals who historically have encountered access to care barriers. Dental education has to accept the responsibility to prepare future dental care providers to be able to treat patients from underserved groups.

Dr. Brown is a graduate student in orthodontics, Department of Orthodontics and Pediatric Dentistry, School of Dentistry, University of Michigan; and Dr. Inglehart is Associate Professor, Department of Periodontics and Oral Medicine, School of Dentistry and Department of Psychology, College of Literature, Science, and Arts, University of Michigan. Direct correspondence and requests for reprints to Dr. Marita Rohr Inglehart, Department of Periodontics and Oral Medicine, School of Dentistry, University of Michigan, 1011 North University Avenue, Ann Arbor, MI 48109-1078; 734-763-8073 phone; 734-763-5503 fax; mri@umich.edu.

This study was supported by a grant from the Delta Dental Foundation in Michigan to the first author.

Key words: orthodontics, access to care, dental education, ethnic/racial minorities, professional attitudes, craniofacial anomalies, special needs patients, Medicaid, pro bono, mental retardation

Submitted for publication 10/8/08; accepted 2/12/09

$\mathrm{I}$ n 2000, the U.S. surgeon general's report on oral health described in clear and unequivocal terms the oral health disparities and the disparities in access to oral health care that exist in the United States. ${ }^{1}$ This report focused in particular on demonstrating that members from underrepresented minority groups, socioeconomically disadvantaged patients, and patients with special needs had disproportionately high levels of caries and periodontal disease and increased problems with finding access to oral health care services. While these disparities in the access to preventive and operative care are a serious problem by themselves, they are also likely to affect the degree to which members from these underserved groups have access to specialty care such as orthodontic treatment. Hunt et al., for example, summarized evidence showing that general dental practitioners have a strong influence on patients' decisions to seek and undergo orthodontic treatment. ${ }^{2}$ Any lack of general dental care would therefore likely affect patients' chances to be referred for orthodontic care. In addition, orthodontic care is even less likely to be covered by private dental insurance plans and Medicaid compared to other procedures provided by general dentists. ${ }^{1}$ Orthodontic treatment might also be considered to be an elective treatment. ${ }^{3,4}$ It is therefore not surprising that access to orthodontic 
care is a major problem for patients from underserved groups.

Given the barriers for underserved patients to receiving orthodontic care, it is interesting to reflect on the extent of the need for orthodontic care in the United States. From 1988 to 1991, the third National Health and Nutrition Examination Survey (NHANES-III) collected data from approximately 7,000 adults and children about the prevalence of malocclusion and orthodontic treatment need among these respondents. ${ }^{5}$ The results found that approximately 15 percent of the sample had a definite orthodontic treatment need, with malocclusion being severe enough to affect both social acceptability and oral functioning. Furthermore, this survey found that 57 to 59 percent of the U.S. population had some degree of orthodontic treatment need. ${ }^{6}$

Given these high percentages of U.S. citizens with orthodontic treatment needs, it is important to understand that severe malocclusion can be the root of social discrimination and can create problems with oral function and hygiene. ${ }^{6}$ In short, severe malocclusion can impact an individual's entire life. For example, Shaw reported that children with normal dental esthetics were judged to be more intelligent by their teachers, more desirable as friends, and better looking ${ }^{7}$ compared to children with an orthodontic treatment need. School-aged children were also subject to more teasing if they had a severe malocclusion. ${ }^{8}$ Individuals with malocclusions may develop feelings of shame, which can lead to problems with uneasiness in social settings. ${ }^{9}$ More recent research has found that malocclusion can affect the smile-related aspects of children's oral health-related quality of life..${ }^{3,4}$ Given the prevalence of orthodontic treatment need and the detrimental effects of severe malocclusions on an individual's life, it seems important to understand how access to orthodontic care for patients from underserved groups can be increased.

Noonan and Evans have pointed out that dental education can and should play a pivotal role in reducing oral health disparities and problems with access to oral health care services. ${ }^{10}$ Terrell and Beaudreau have argued that dental schools have the responsibility of preparing dental professionals in such a way that they accept their civic responsibility concerning providing care for underserved patients. ${ }^{11}$ Novak et al. found that dental curricula with diversity-specific subject matter affected students' perceived ability to treat diverse populations. ${ }^{12}$ Specifically, several studies of general dentists and dental students found that the better these providers evaluated their educational preparation to provide care for patients with special needs, ${ }^{13}$ patients from different ethnic/racial backgrounds and/or patients from socioeconomically disadvantaged backgrounds, ${ }^{14}$ and pediatric patients, ${ }^{15}$ the more positive their professional attitudes and behaviors were concerning the treatment of these patients. The absence of culturally competent dental education can lead to a lack of confidence in the ability to effectively treat patients from certain groups - and this lack of confidence might ultimately affect providers' willingness to treat these patients. ${ }^{14}$ Collectively, these studies ${ }^{12-15}$ indicate that predoctoral dental education has the potential to positively affect both the confidence and the attitudes of students concerning the treatment of patients from underserved groups. Indeed, the absence of education about the health care needs of underserved populations can influence practitioners' practice attitudes and associated behaviors. Burtner and Dicks, for example, found that dentists' willingness to provide care for patients with special needs was negatively affected by poor attitudes towards patients with special needs. ${ }^{16} \mathrm{In}$ turn, positive attitudes become part of the motivation to provide care for these patients. ${ }^{17}$

While the role of predoctoral dental education as a way to affect providers' willingness to treat patients from underserved groups has been explored by several investigators, no research so far has analyzed whether graduate dental education could also play an important role in this context. The purpose of our study, therefore, was to analyze the degree to which residents and practitioners with one specific type of graduate dental education - namely, orthodontic residency training perceived that their graduate orthodontic education had prepared them well to treat underserved patients and whether this education affected their professional attitudes and behavior concerning providing care for members of historically underserved patient groups. The groups specifically considered in this study were patients from ethnic/racial minority groups; patients from socioeconomically disadvantaged backgrounds (such as patients covered by Medicaid or without dental insurance); and patients with special needs (such as craniofacial anomalies and developmental delays).

\section{Methods}

This research was approved by the Institutional Review Board for the Health Sciences at the University of Michigan (\# HUM00014104).

Data were collected from 135 orthodontic residents and 568 active members of the American 
Association of Orthodontists (AAO). Table 1 provides an overview of the demographic and practice characteristics of the two respondent groups. The first group included 135 of the approximately 325 orthodontic residents from U.S. and Canadian graduate orthodontic programs who attended the 2007 Graduate Orthodontic Residents Program (GORP) in St. Louis, Missouri (response rate: 41.54 percent). The second group consisted of 568 practicing orthodontists who responded to an anonymous survey that was mailed to 1,500 randomly selected AAO members (response rate: 37.87 percent). The majority of respondents in both groups were male (residents: 61.5 percent; orthodontists: 79 percent) and from a European American background (residents: 64.4 percent; orthodontists: 88.2 percent).

The graduate student data were collected at the GORP meeting in August 2007. Residents from all U.S. and Canadian orthodontic residency programs were invited to attend this annual meeting. When the graduate students arrived and registered for the conference, they received a letter explaining the study, a consent script, the survey, and a return envelope to anonymously place the survey in a box at the registration desk. The students were informed that they could participate in a drawing for an iPod shuffle after returning the survey and filling out a separate form with their name and address.

The data from the practicing orthodontists were collected with a mailed survey sent to a random sample of 1,500 active AAO members. The address labels for this mailing were purchased from the AAO. The mailing included a cover letter from the dean of the University of Michigan School of Dentistry informing AAO members about the study and encouraging them to respond to the survey; the package also contained a consent script, a survey, and a self-addressed stamped envelope in which the respondents could return the survey to the researchers.

The surveys for both groups assessed the respondents' demographic and practice characteristics as well as their educational experiences concerning providing care for members of three patient groups described as underserved in the surgeon general's report on oral health. ${ }^{1}$ These groups were patients from underrepresented racial/ethnic populations; socioeconomically disadvantaged patients, namely patients on Medicaid and pro bono cases; and special

Table 1. Demographic and practice characteristics of the two respondent groups in this study, by percentage of total respondents in each group

\begin{tabular}{|c|c|c|c|}
\hline & $\begin{array}{c}\text { Residents } \\
\mathrm{N}=135\end{array}$ & $\begin{array}{c}\text { Orthodontists } \\
\quad \mathrm{N}=568\end{array}$ & $\mathrm{p}$ \\
\hline \multicolumn{4}{|l|}{ Gender } \\
\hline $\begin{array}{l}\text { Male } \\
\text { Female }\end{array}$ & $61.5 \%$ & $79 \%$ & $\mathrm{p}<.001$ \\
\hline \multicolumn{4}{|l|}{ Age } \\
\hline $\begin{array}{l}\text { Mean } \\
\text { SD } \\
\text { Range }\end{array}$ & $\begin{array}{c}28.67 \\
3.005 \\
23 \text { to } 43\end{array}$ & $\begin{array}{c}48.03 \\
10.942 \\
28 \text { to } 75\end{array}$ & $\mathrm{p}<.001$ \\
\hline \multicolumn{4}{|l|}{ Ethnicity/race } \\
\hline $\begin{array}{l}\text { African American } \\
\text { Asian American } \\
\text { European American } \\
\text { Latino/Hispanic } \\
\text { Biracial } \\
\text { Others }\end{array}$ & $\begin{array}{l}3 \% \\
17.4 \% \\
64.4 \% \\
5.3 \% \\
0 \\
9.9 \%\end{array}$ & $\begin{array}{c}2.3 \% \\
5.4 \% \\
88.2 \% \\
2.5 \% \\
1.2 \% \\
4 \%\end{array}$ & $\mathrm{p}<.001$ \\
\hline \multicolumn{4}{|l|}{ Practice Characteristics } \\
\hline $\begin{array}{l}\text { Years of practicing } \\
\text { Mean } \\
\text { SD } \\
\text { Range }\end{array}$ & $\mathrm{N} / \mathrm{A}$ & $\begin{array}{c}18.13 \\
10.803 \\
0 \text { to } 44\end{array}$ & N/A \\
\hline $\begin{array}{l}\text { Which best describes your practice/employment situation? } \\
\text { Solo practice } \\
\text { Partnership } \\
\text { Associateship } \\
\text { Other }\end{array}$ & $\mathrm{N} / \mathrm{A}$ & $\begin{array}{l}73 \% \\
19 \% \\
4.2 \% \\
3.7 \%\end{array}$ & N/A \\
\hline
\end{tabular}


needs patients, such as individuals with craniofacial anomalies and developmental delays. In addition, the respondents' professional attitudes concerning the treatment of these patient groups were assessed. The residents were asked to indicate their behavioral intentions concerning providing care for these patients in their future professional lives. Practicing orthodontists were asked about their current professional behavior concerning providing care for members of underserved patient groups.

Two separate factor analyses (extraction method: Principal Component Analysis; rotation method: Varimax with Kaiser Normalization) were conducted to identify the underlying factorial structures of a series of survey items that addressed educational components of the respondents' residency program and several items designed to measure attitudes concerning treating patients from these underserved groups.

The survey included eighteen educational items designed to elicit the respondents' perceptions of the quality of their classroom-based, clinic-based, and community-based education about treating members of the three patient groups: individuals from diverse ethnic backgrounds; patients on Medicaid and/or without dental insurance and other means to pay for services (i.e., pro bono cases); and patients with special needs (i.e., patients with craniofacial anomalies, developmental disabilities/delays, and special needs other than craniofacial anomalies or developmental delays). The specific wording of these items is shown in Tables 2 and 3. The first factor analysis resulted in three factors. The first factor was concerned with education about treating patients with diverse multicultural backgrounds; three items loaded on this factor. The reliability coefficient for this first index was Cronbach's alpha $=.740$. Six items loaded on the second factor; these items were concerned with education about treating patients on Medicaid and pro bono cases. These six items were combined into one index concerning education about patients with socioeconomic issues. The reliability coefficient for

Table 2. Respondents' assessment of their educational experiences concerning patients from different ethnic backgrounds and Medicaid and pro bono cases, by percentage of total respondents in each category

\begin{tabular}{llrrrr} 
& Respondents & $1 \& 2$ & 3 & $4 \& 5$ & \\
\hline Different Ethnic Backgrounds & & & & \\
My classroom education in orthodontics prepared me well & Residents & $2.4 \%$ & $19.5 \%$ & $78.0 \%$ & 4.28 \\
to treat patients from different ethnic/racial backgrounds. & Orthodontists & $8.3 \%$ & $11.7 \%$ & $80.0 \%$ & 4.23 \\
My clinical education in orthodontics prepared me well to & Residents & $.8 \%$ & $12.8 \%$ & $86.4 \%$ & 4.49 \\
treat patients from different ethnic/racial backgrounds. & Orthodontists & $6.5 \%$ & $11.3 \%$ & $82.3 \%$ & $4.32 *$ \\
My community-based education in orthodontics prepared & Residents & $8.3 \%$ & $24.8 \%$ & $66.9 \%$ & 4 \\
me well to treat patients from different ethnic/racial & Orthodontists & $15.6 \%$ & $16.9 \%$ & $67.5 \%$ & 3.91
\end{tabular}

backgrounds.

\section{Medicaid and Pro Bono Cases}

My classroom education in orthodontics prepared me well to treat patients on Medicaid.

My clinical education in orthodontics prepared me well to treat patients on Medicaid.

My community-based education in orthodontics prepared me well to treat patients on Medicaid.

My classroom education in orthodontics prepared me well to treat pro bono cases.

My clinical education in orthodontics prepared me well to treat pro bono cases.

My community-based education in orthodontics prepared me well to treat pro bono cases.

$\begin{array}{lrrrl}\text { Residents } & 14.4 \% & 30.5 \% & 55.1 \% & 3.62 \\ \text { Orthodontists } & 51.5 \% & 21.8 \% & 26.9 \% & 2.63^{* * *} \\ \text { Residents } & 9.8 \% & 25.4 \% & 64.7 \% & 3.83 \\ \text { Orthodontists } & 43.6 \% & 22.1 \% & 34.4 \% & 2.88^{* * *} \\ \text { Residents } & 9.4 \% & 31.3 \% & 59.5 \% & 3.73 \\ \text { Orthodontists } & 45.9 \% & 24.7 \% & 29.4 \% & 2.71^{* * *} \\ \text { Residents } & 18.3 \% & 37.5 \% & 44.1 \% & 3.41 \\ \text { Orthodontists } & 39.6 \% & 28.3 \% & 32.1 \% & 2.85^{* * *} \\ \text { Residents } & 22.3 \% & 32.2 \% & 45.4 \% & 3.36 \\ \text { Orthodontists } & 39.5 \% & 27.2 \% & 33.4 \% & 2.9^{* * *} \\ \text { Residents } & 15.0 \% & 42.1 \% & 43.0 \% & 3.41 \\ \text { Orthodontists } & 22.4 \% & 28.9 \% & 38.6 \% & 3.06^{* *}\end{array}$

Note: Answers were given on five-point answer scales from 1 =disagree strongly to $5=$ agree strongly. Responses " 1 " and " 2 " were combined, and responses " 4 " and " 5 " were combined. Percentages may not total $100 \%$ because of rounding.

${ }^{*} \mathrm{p}<.05 ; * * \mathrm{p}<.01 ; * * * \mathrm{p}<.001$ 
Table 3. Respondents' assessment of their educational experiences concerning patients with various special needs, by percentage of total respondents in each category

Respondents $\quad 1 \& 2 \quad 3 \quad 4 \& 5 \quad$ Mean

\section{Special Needs}

My classroom education in orthodontics prepared me well to treat patients with special needs.

$\begin{array}{lllll}\text { Residents } & 16.3 \% & 39.0 \% & 44.7 \% & 3.43 \\ \text { Orthodontists } & 44.5 \% & 29.4 \% & 26.2 \% & 2.73^{* * *} \\ \text { Residents } & 13.0 \% & 34.1 \% & 52.8 \% & 3.57 \\ \text { Orthodontists } & 39.4 \% & 25.6 \% & 35.0 \% & 2.91^{* * *} \\ \text { Residents } & 19.6 \% & 43.0 \% & 37.4 \% & 3.25 \\ \text { Orthodontists } & 24.8 \% & 32.6 \% & 32.6 \% & 2.9 * *\end{array}$

My clinical education in orthodontics prepared me well to treat patients with special needs.

My community-based education in orthodontics prepared me well to treat patients with special needs.

Orthodontists

$24.8 \%$

$\begin{array}{lrrrl}\text { Residents } & 6.4 \% & 30.6 \% & 62.9 \% & 3.81 \\ \text { Orthodontists } & 23.4 \% & 26.0 \% & 50.6 \% & 3.43^{* * *} \\ \text { Residents } & 9.7 \% & 25.0 \% & 65.3 \% & 3.84 \\ \text { Orthodontists } & 24.7 \% & 22.6 \% & 52.6 \% & 3.44 * * * \\ \text { Residents } & 15.6 \% & 43.0 \% & 35.8 \% & 3.31 \\ \text { Orthodontists } & 35.4 \% & 30.9 \% & 33.7 \% & 2.92^{* *}\end{array}$

My community-based education in orthodontics prepared me well to treat patients with craniofacial anomalies.

\section{Craniofacial Anomalies}

My classroom education in orthodontics prepared me well to treat patients with craniofacial anomalies.

My clinical education in orthodontics prepared me well to treat patients with craniofacial anomalies.

\section{Mental Retardation}

My classroom education in orthodontics prepared me well to treat patients with mental retardation.

My clinical education in orthodontics prepared me well to treat patients with mental retardation.

My community-based education in orthodontics prepared me well to treat patients with mental retardation.

$\begin{array}{lllll}\text { Residents } & 21.1 \% & 42.3 \% & 36.6 \% & 3.21 \\ \text { Orthodontists } & 52.1 \% & 27.6 \% & 20.4 \% & 2.53 * * * \\ \text { Residents } & 16.3 \% & 38.2 \% & 45.5 \% & 3.39 \\ \text { Orthodontists } & 44.8 \% & 24.7 \% & 30.5 \% & 2.73 * * * \\ \text { Residents } & 21.5 \% & 43.0 \% & 35.5 \% & 3.18 \\ \text { Orthodontists } & 38.6 \% & 34.0 \% & 27.5 \% & 2.78^{* *}\end{array}$

Note: Answers were given on five-point answer scales from 1 =disagree strongly to $5=$ agree strongly. Responses " 1 " and " 2 " were combined, and responses " 4 " and " 5 " were combined. Percentages may not total $100 \%$ because of rounding.

${ }^{* *} \mathrm{p}<.01 ;{ }^{* * *} \mathrm{p}<.001$

the six items combined into this index was Cronbach's alpha $=.886$. Nine items concerning the treatment of patients with craniofacial anomalies, developmental delays, and special needs loaded on a third factor. These items were combined into the third educational index, and the reliability coefficient for these nine items was Cronbach's alpha=.934.

The second factor analysis included responses to the eight items concerning attitudes towards treating patients from underserved groups. (For wording of the items, see Table 4.) The rotated component matrix showed that the items loaded on three factors. These three factors were concerned with attitudes towards providing care for patients from diverse multicultural populations (two items); Medicaid patients and pro bono cases (two items); and patients with craniofacial anomalies and developmental delays (four items). Based on these factor analysis results, three indices were constructed by averaging the responses to the items loading on each of these three factors. Analyses using the Cronbach's alpha coefficient found that the reliability of items that loaded on a factor "Attitudes about treating a diverse multicultural population of patients" was 0.754 , that the reliability of items that loaded on a factor "Medicaid patients and pro bono cases" was 0.316 , and that the reliability of items loading on a factor "Attitudes towards patients with craniofacial anomalies and developmental delays" was 0.782 .

One additional consideration was that the orthodontists reported their actual professional behavior concerning the treatment of patients from underserved groups, while the orthodontic residents reported their intentions to treat these patients in their future professional lives. If the actual numbers of patients treated by the residents at the time of the survey had been included in these analyses, this variable would not have reflected the residents' 
Table 4. Professional attitudes concerning the treatment of patients with specified characteristics, by percentage of total respondents in each category

Respondents $\quad 1 \& 2 \quad 3 \quad 3 \& 5 \quad$ Mean

\section{Diverse Ethnic Backgrounds}

I like to treat patients from different ethnic backgrounds.

My practice (will) include(s) patients from ethnic

backgrounds that are different from my own background.

$\begin{array}{lrrrl}\text { Residents } & 1.5 \% & 6.8 \% & 91.7 \% & 4.5 \\ \text { Orthodontists } & 1.2 \% & 9.1 \% & 89.7 \% & 4.55 \\ \text { Residents } & .8 \% & 6.0 \% & 93.3 \% & 4.62 \\ \text { Orthodontists } & 3.8 \% & 2.3 \% & 93.8 \% & 4.7 \\ & & & & \\ & & & & \\ \text { Residents } & 29.1 \% & 36.2 \% & 34.7 \% & 3.02 \\ \text { Orthodontists } & 69.3 \% & 19.7 \% & 11.0 \% & 1.99 * * * \\ \text { Residents } & 9.3 \% & 28.9 \% & 61.7 \% & 3.87 \\ \text { Orthodontists } & 21.0 \% & 28.4 \% & 50.6 \% & 3.45^{* * *} \\ & & & & \\ & & & & \\ \text { Residents } & 6.2 \% & 40.0 \% & 53.8 \% & 3.64 \\ \text { Orthodontists } & 30.8 \% & 38.0 \% & 21.2 \% & 3.01^{* * *} \\ \text { Residents } & 39.0 \% & 32.8 \% & 28.2 \% & 2.86 \\ \text { Orthodontists } & 24.7 \% & 24.9 \% & 50.4 \% & 3.37^{* * *} \\ \text { Residents } & 23.0 \% & 46.0 \% & 30.9 \% & 3.13 \\ \text { Orthodontists } & 41.4 \% & 38.1 \% & 20.6 \% & 2.72^{* * *} \\ \text { Residents } & 33.8 \% & 35.4 \% & 30.7 \% & 2.97 \\ \text { Orthodontists } & 26.2 \% & 25.9 \% & 48.0 \% & 3.31^{* *}\end{array}$

Medicaid and Pro Bono Cases

I like to treat patients on Medicaid.

I like to treat patients as pro bono cases.

Craniofacial Anomalies and Developmental Delays

I like to treat patients with craniofacial anomalies.

I am confident treating patients with craniofacial anomalies.

I like to treat patients with mental retardation.

I am confident treating patients with mental retardation.

Orthodontis

Note: Answers were given on five-point answer scales from 1 =disagree strongly to $5=$ agree strongly. Responses " 1 " and " 2 " were combined, and responses " 4 " and " 5 " were combined. Percentages may not total $100 \%$ because of rounding.

$* * \mathrm{p}<.01 ; * * * \mathrm{p}<.001$

own motivation for treating underserved patients, because during residency programs the graduate students treat assigned patients and cannot freely choose whom they would like to treat. Therefore, the respondents indicated their behavioral intentions concerning treating underserved patients in the future because research has found that behavioral intentions are the best predictors of future behavior. ${ }^{18}$ In order to construct a behavioral indicator, the numerical responses of the orthodontists concerning how many patients from a certain group they treated were dichotomized into the categories "I do not treat" versus "I do treat" these patients. The responses of the orthodontic residents concerning the question "I will treat patients from these different groups" were provided on five-point answer scales ranging from "disagree strongly" to "agree strongly." The responses " 1 " to " 3 " (disagree strongly, disagree, neutral) were categorized as an indication of not being likely to treat these patients, and the responses " 4 " and " 5 " (agree and agree strongly) were categorized as having a behavioral intention to treat these patients. By categorizing the actual professional behaviors of the orthodontists and the behavioral intentions of the orthodontic residents, a behavioral dependent variable was created that was used in Tables 5 to 7.

The data were analyzed with SPSS, version 16.0 (SPSS Inc., Chicago, IL). Factor analyses were used to construct educational and attitudinal indices. The reliability of these scales was determined by computing a Cronbach's alpha reliability coefficient for each scale. Descriptive statistics (percentages, means) were used to provide an overview of the distribution of respondents' answers concerning the concepts of interest (Tables 1 to 5). Correlational analyses with Pearson correlation coefficients were performed to determine whether the educational background responses and the attitudinal responses correlated as predicted (Table 6). Five multivariate analyses of variance with the three educational indices as the dependent variables and the two factors "Type of provider: orthodontists vs. residents" and "Care provided: yes/no" were conducted for each of the five types of patient groups (Table 7). A p-value of $<0.05$ was considered statistically significant. 


\section{Results}

Table 1 provides an overview of demographic and practice characteristics of the residents and orthodontists participating in this study. This table shows that while both groups of respondents were more likely to be male, the percentage of female residents was larger than the percentage of female orthodontists (38.5 percent versus 21 percent; $\mathrm{p}<.001$ ). Residents were, of course, on average significantly younger than orthodontists (28.67 years versus 48.03 years;

Table 5. Percentages of orthodontists and residents who provide care for different groups of patients, by percentage of total respondents in each category

\begin{tabular}{lcc} 
Type of Patient & $\begin{array}{c}\text { Residents }^{\mathrm{a}} \\
\text { I will treat }\end{array}$ & $\begin{array}{c}\text { Orthodontists } \\
\text { I provide care for }\end{array}$ \\
\hline Patients from different ethnic backgrounds & $89.7 \%$ & $90.7 \%^{\mathrm{b}}$ \\
Patients on Medicaid & $36.3 \%$ & $35.7 \%^{\mathrm{c}}$ \\
Pro bono cases & $71.9 \%$ & $83.1 \%^{\mathrm{c} * *}$ \\
Patients with craniofacial anomalies & $52.3 \%$ & $82.9 \%^{\mathrm{c} * * *}$ \\
Patients with mental retardation/developmental delays & $53.3 \%$ & $81.5 \%^{\mathrm{c} * * *}$
\end{tabular}

${ }^{* *} \mathrm{p}<.01 ; * * * \mathrm{p}<.001$

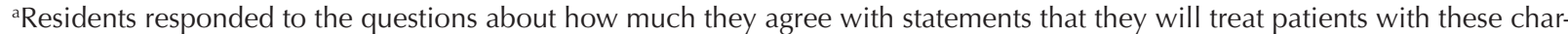
acteristics in their future professional lives. Responses " 1 " (disagree strongly), "2" (disagree), and "3" (neutral) were coded as " 0 " (will not treat in the future). Responses "4" (agree) and "5" (agree strongly) were coded as "yes" (will treat in the future). bOrthodontists responded to the statement "My practice includes patients from all ethnic backgrounds" on a five-point answer scale. Responses "1" (disagree strongly), "2" (disagree), and "3" (neutral) were coded as "0" (will not treat in the future). Responses " 4 " (agree) and "5" (agree strongly) were coded as "yes" (will treat in the future).

cThe reported number of patients treated with each characteristic was categorized into "0 patients treated" ="no patients treated" versus "more than 0 patients treated"="yes, patients with this characteristic treated."

Table 6. Correlations of responses concerning education with professional attitudes and behaviors

Education Concerning Patient With/From

\begin{tabular}{|c|c|c|c|c|}
\hline & $\begin{array}{l}\text { Respondent } \\
\text { Type }\end{array}$ & $\begin{array}{c}\text { Different } \\
\text { Racial/Ethnic } \\
\text { Backgrounds }\end{array}$ & $\begin{array}{l}\text { Medicaid } \\
\text { and } \\
\text { Pro Bono }\end{array}$ & $\begin{array}{c}\text { Craniofacial } \\
\text { Anomalies, } \\
\text { Retardation, or } \\
\text { Special Needs }\end{array}$ \\
\hline \multicolumn{5}{|l|}{ Attitude toward treating patients with } \\
\hline Diverse backgrounds & $\begin{array}{l}\text { Residents } \\
\text { Orthodontists }\end{array}$ & $\begin{array}{l}\mathrm{r}=.397^{* * *} \\
\mathrm{r}=.399^{* * *}\end{array}$ & $\begin{array}{l}r=.234^{*} \\
r=.098^{*}\end{array}$ & $\begin{array}{l}r=.109 \\
r=.137^{*}\end{array}$ \\
\hline Socioeconomic disadvantages, Medicaid, pro bono & $\begin{array}{l}\text { Residents } \\
\text { Orthodontists }\end{array}$ & $\begin{array}{l}\mathrm{r}=.363^{* * *} \\
\mathrm{r}=.052\end{array}$ & $\begin{array}{l}\mathrm{r}=.392 * * * \\
\mathrm{r}=.345^{* * *}\end{array}$ & $\begin{array}{l}\mathrm{r}=.094 \\
\mathrm{r}=.230^{* * *}\end{array}$ \\
\hline Craniofacial anomalies or mental retardation & $\begin{array}{l}\text { Residents } \\
\text { Orthodontists }\end{array}$ & $\begin{array}{l}r=.146 \\
r=.170^{* * *}\end{array}$ & $\begin{array}{l}\mathrm{r}=.196 \\
\mathrm{r}=.204 * * *\end{array}$ & $\begin{array}{l}\mathrm{r}=.500^{* * *} \\
\mathrm{r}=.549^{* * *}\end{array}$ \\
\hline \multicolumn{5}{|l|}{ Behavior toward treating patients with } \\
\hline Diverse backgrounds & $\begin{array}{l}\text { Residents } \\
\text { Orthodontists }\end{array}$ & $\begin{array}{l}\mathrm{r}=.281^{* *} \\
\mathrm{r}=.233^{* * *}\end{array}$ & $\begin{array}{l}r=.235^{*} \\
r=.072\end{array}$ & $\begin{array}{l}r=.114 \\
r=.108^{*}\end{array}$ \\
\hline Medicaid & $\begin{array}{l}\text { Residents } \\
\text { Orthodontists }\end{array}$ & $\begin{array}{l}r=-.007 \\
r=-.077\end{array}$ & $\begin{array}{l}r=.147 \\
r=.092^{*}\end{array}$ & $\begin{array}{l}r=.108 \\
r=.011\end{array}$ \\
\hline Pro bono & $\begin{array}{l}\text { Residents } \\
\text { Orthodontists }\end{array}$ & $\begin{array}{l}r=.411 * * * \\
r=-.052\end{array}$ & $\begin{array}{l}\mathrm{r}=.360^{* * *} \\
\mathrm{r}=.134^{*}\end{array}$ & $\begin{array}{l}r=.094 \\
r=.07\end{array}$ \\
\hline Craniofacial anomalies & $\begin{array}{l}\text { Residents } \\
\text { Orthodontists }\end{array}$ & $\begin{array}{l}r=.149 \\
r=.081\end{array}$ & $\begin{array}{l}r=.237^{*} \\
r=.057\end{array}$ & $\begin{array}{l}\mathrm{r}=.411^{* * *} \\
\mathrm{r}=.192^{* * *}\end{array}$ \\
\hline Mental retardation/developmental disabilities & $\begin{array}{l}\text { Residents } \\
\text { Orthodontists }\end{array}$ & $\begin{array}{l}r=.018 \\
r=.081\end{array}$ & $\begin{array}{l}r=.118 \\
r=.026\end{array}$ & $\begin{array}{l}\mathrm{r}=.254^{* *} \\
\mathrm{r}=.127^{*}\end{array}$ \\
\hline
\end{tabular}


Table 7. Educational experiences of orthodontists versus residents who provide care versus do not provide care for underserved patients

Education About Patient Groups

\begin{tabular}{|c|c|c|c|c|c|}
\hline I provide care for patients from/with & & $\begin{array}{l}\text { Respondent } \\
\text { Type }\end{array}$ & $\begin{array}{c}\text { Ethnic } \\
\text { Backgroundt }\end{array}$ & $\begin{array}{l}\text { Medicaid/ } \\
\text { Pro Bono } \neq\end{array}$ & $\begin{array}{l}\text { Special } \\
\text { Needs§ }\end{array}$ \\
\hline \multirow[t]{2}{*}{ Diverse backgrounds } & Yes & $\begin{array}{l}\text { Residents } \\
\text { Orthodontists }\end{array}$ & $\begin{array}{l}4.29 \\
4.19\end{array}$ & $\begin{array}{l}3.64 \\
2.84\end{array}$ & $\begin{array}{l}3.43 \\
2.94\end{array}$ \\
\hline & No & $\begin{array}{l}\text { Residents } \\
\text { Orthodontists }\end{array}$ & $\begin{array}{c}3.52 \\
3.47 \\
p<.001\end{array}$ & $\begin{array}{c}2.86 \\
2.60 \\
p=.024\end{array}$ & $\begin{array}{c}3.00 \\
2.59 \\
p=.056\end{array}$ \\
\hline \multirow[t]{2}{*}{ Medicaid } & Yes & $\begin{array}{l}\text { Residents } \\
\text { Orthodontists }\end{array}$ & $\begin{array}{l}4.27 \\
4.02\end{array}$ & $\begin{array}{l}3.75 \\
2.95\end{array}$ & $\begin{array}{l}3.56 \\
2.93\end{array}$ \\
\hline & No & $\begin{array}{l}\text { Residents } \\
\text { Orthodontists }\end{array}$ & $\begin{array}{c}4.22 \\
4.18 \\
p=.596\end{array}$ & $\begin{array}{c}3.45 \\
2.75 \\
p=.042\end{array}$ & $\begin{array}{c}3.31 \\
2.89 \\
p=.204\end{array}$ \\
\hline \multirow[t]{2}{*}{ Pro bono } & Yes & $\begin{array}{l}\text { Residents } \\
\text { Orthodontists }\end{array}$ & $\begin{array}{l}4.43 \\
4.11\end{array}$ & $\begin{array}{l}3.78 \\
2.89\end{array}$ & $\begin{array}{l}3.47 \\
2.94\end{array}$ \\
\hline & No & $\begin{array}{l}\text { Residents } \\
\text { Orthodontists }\end{array}$ & $\begin{array}{c}3.78 \\
4.20 \\
p=.015\end{array}$ & $\begin{array}{c}3.04 \\
2.46 \\
p<.001\end{array}$ & $\begin{array}{c}3.22 \\
2.73 \\
p=.063\end{array}$ \\
\hline \multirow[t]{2}{*}{ Craniofacial anomalies } & Yes & $\begin{array}{l}\text { Residents } \\
\text { Orthodontists }\end{array}$ & $\begin{array}{l}4.34 \\
4.15\end{array}$ & $\begin{array}{l}3.75 \\
2.85\end{array}$ & $\begin{array}{l}3.72 \\
2.99\end{array}$ \\
\hline & No & $\begin{array}{l}\text { Residents } \\
\text { Orthodontists }\end{array}$ & $\begin{array}{c}4.08 \\
4.00 \\
p=.062\end{array}$ & $\begin{array}{c}3.27 \\
2.67 \\
p=.010\end{array}$ & $\begin{array}{c}2.90 \\
2.52 \\
p<.001\end{array}$ \\
\hline \multirow[t]{2}{*}{ Mental retardation/developmental disabilities } & Yes & $\begin{array}{l}\text { Residents } \\
\text { Orthodontists }\end{array}$ & $\begin{array}{l}4.25 \\
4.09\end{array}$ & $\begin{array}{l}3.68 \\
2.83\end{array}$ & $\begin{array}{l}3.65 \\
2.97\end{array}$ \\
\hline & No & $\begin{array}{l}\text { Residents } \\
\text { Orthodontists }\end{array}$ & $\begin{array}{c}4.23 \\
4.25 \\
p=.519\end{array}$ & $\begin{array}{c}3.44 \\
2.76 \\
p=.218\end{array}$ & $\begin{array}{c}3.14 \\
2.66 \\
p<.001\end{array}$ \\
\hline
\end{tabular}

Note: The p value indicates whether the interaction effect of "type of respondent" x "Provides care for . . : : yes/no" is significant.

Three average educational responses are reported for each respondent group:

tThe first score is the average response to the three items concerned with treating patients from different ethnic/racial backgrounds.

\#The second score is the average response to the six items concerned with treating patients with Medicaid and pro bono cases. $\S$ The third score is the average response to the nine items concerned with treating patients with craniofacial anomalies, mental retardation, and other special needs.

$\mathrm{p}<.001)$. While both residents and orthodontists were predominantly European Americans, residents were more likely to come from other backgrounds compared to orthodontists (35.6 percent versus 11.8 percent; $\mathrm{p}<.001$ ).

Information about the practice characteristics of the orthodontists showed that they had on average practiced for 18.13 years (range: 0 to 44 years) and that most of the orthodontists ( 73 percent) practiced in solo practices and in partnership practices (19 percent).

\section{Educational Experiences in Treating Underserved Groups}

Tables 2 and 3 provide descriptive statistics concerning the residents' and orthodontists' perceptions of the quality of their own educational experiences in treating members from underserved patient groups. Responses concerning educational experiences with patients from diverse ethnic backgrounds showed that a large majority of both residents and orthodontists agreed/agreed strongly with the state- 
ments that they were well prepared to treat patients from diverse multicultural backgrounds in their clinical education (residents: 86.4 percent; orthodontists: 82.3 percent) and that their classroom education in orthodontics had prepared them well to treat patients from multicultural backgrounds (78 percent; 80 percent). However, slightly smaller percentages agreed/agreed strongly that their community-based education had prepared them well (66.9 percent; 67.5 percent).

Concerning educational experiences in treating socioeconomically disadvantaged patients such as patients on Medicaid and pro bono cases, Table 2 shows that lower percentages of residents and especially orthodontists agreed/agreed strongly with the statement that their classroom education in orthodontics had prepared them well to treat patients on Medicaid (residents: 55.1 percent; orthodontists: 26.9 percent) in comparison to their assessment of preparation for treating a diverse multicultural patient pool. Residents also said they felt better prepared by their clinical experiences and their community-based graduate education about treating patients on Medicaid compared to orthodontists (in clinical education, residents: 64.7 percent and orthodontists: 34.4 percent; in community-based education, residents: 59.5 percent and orthodontists: 29.4 percent).

The percentages of residents and orthodontists who agreed/agreed strongly that their graduate education had prepared them well to treat pro bono cases were also considerably lower than the percentages of agreement with statements concerning education about treating patients from diverse ethnic/racial backgrounds. Again, the residents reported that they felt significantly better prepared than the orthodontists did on average (on a five-point scale from $1=$ disagree strongly to $5=$ agree strongly -in classroom education, residents: 3.41 and orthodontists: 2.85 [ $<<.001]$; in clinical education, residents: 3.36 and orthodontists: 2.9 [p<.001]; and in communitybased education, residents: 3.41 and orthodontists: $3.06[\mathrm{p}<.01])$.

Table 3 shows the responses concerning educational experiences in treating patients with special needs, craniofacial anomalies, and mental retardation. Concerning treating patients with special needs in general, residents said they feel significantly better prepared in all three educational settings compared to orthodontists. This pattern of responses was also found for answers to the items concerning the quality of education about treating patients with craniofacial anomalies and mental retardation. However, rela- tively higher percentages of both residents and orthodontists agreed/agreed strongly with the statement concerning classroom-based education about treating patients with craniofacial anomalies and clinic-based education in orthodontics about treating these patients (in classroom education, residents: 62.9 percent and orthodontists: 50.6 percent; and in clinical education, residents: 65.3 percent and orthodontists: 52.6 percent). The percentages of agreement concerning treating special needs patients in general and treating patients with mental retardation were relatively small compared to the percentages of agreement about treating patients from diverse multicultural and lower socioeconomic backgrounds.

\section{Professional Attitudes and Professional Behavior}

Table 4 provides an overview of professional attitudes concerning the treatment of patients from the three groups of interest. This table shows that the majority of residents and orthodontists said they like to treat patients from diverse ethnic backgrounds and that their practice includes/will include patients from ethnic backgrounds different from their own (residents: 91.7 percent and 93.3 percent; orthodontists: 89.7 percent and 93.8 percent). Concerning professional attitudes about treating patients on Medicaid and pro bono cases, considerably smaller percentages of residents and orthodontists agreed/agreed strongly that they like to treat patients on Medicaid than that they like to treat patients as pro bono cases. Only 34.7 percent of the residents and 11 percent of the orthodontists agreed/agreed strongly with the statement "I like to treat patients on Medicaid," and only 61.7 percent of residents and 50.6 percent of orthodontists agreed/agreed strongly with the statement that they like to treat pro bono cases. For both of these statements, the residents' level of agreement was significantly higher on average than the average level of the orthodontists' agreement.

Concerning professional attitudes about treating patients with craniofacial anomalies and mental retardation, Table 4 shows that while residents were more likely to agree/agree strongly that they like to treat patients with craniofacial anomalies (53.8 percent) than did orthodontists (21.2 percent), they showed a considerably lower level of agreement with the statement that they are confident treating these patients (residents: 28.2 percent and orthodontists: 50.4 percent). The same pattern was found concerning agreement with the statement "I like to treat patients 
with mental retardation" (residents: 30.9 percent and orthodontists: 20.6 percent) and confidence when "treating patients with mental retardation" (residents: 30.7 percent and orthodontists: 48 percent).

Table 5 provides information about the residents' behavioral intentions to treat patients from these underserved groups in the future and the orthodontists' actual professional behavior. High percentages of respondents from both groups agreed/agreed strongly to treat patients from different ethnic/racial backgrounds (residents: 89.7 percent and orthodontists: 90.7 percent). The lowest percentages of agreement were found for future intentions/actual treatment of Medicaid patients (residents: 36.3 percent and orthodontists: 35.7 percent). Frequency of actual care provided for pro bono cases was relatively high for orthodontists (83.1 percent) although intentions to treat were lower for residents (71.9 percent). A high percentage of orthodontists indicated that they provide care for patients with craniofacial anomalies ( 82.9 percent) and patients with developmental delays ( 81.5 percent), while only slightly more than half of the residents indicated that they intend to provide care for these patients (52.3 percent and 53.3 percent, respectively).

\section{Relationship Between Educational Experiences and Professional Attitudes and Behavior}

A primary goal of this study was to assess the relationship between educational experiences that addressed treatment of underserved patients and the providers' professional attitudes and practice behaviors concerning these patients. Table 6 shows correlations of the educational responses with the professional attitudes and behaviors. The educational experiences were divided into three categories: providing care for 1) a diverse multicultural patient population, 2) patients on Medicaid and pro bono cases, and 3) patients with craniofacial anomalies, developmental delays, and unspecified special needs. As can be seen in Table 6, residents' and orthodontists' evaluations of their education concerning the treatment of patients from diverse ethnic/racial groups are correlated with their attitudes towards treating patients from diverse backgrounds (residents: $\mathrm{r}=.397$, $\mathrm{p}<.001$; and orthodontists: $\mathrm{r}=.399, \mathrm{p}<.001)$ as well as with their behavior (residents: $\mathrm{r}=.281, \mathrm{p}<.01$; and orthodontists: $r=.233, \mathrm{p}<.001)$.

Residents' and orthodontists' evaluations of their educational training concerning providing care for patients from socioeconomically disadvantaged backgrounds correlated significantly with their professional attitudes towards members of this group (residents: $\mathrm{r}=.392, \mathrm{p}<.001$; and orthodontists: $\mathrm{r}=.345$, $\mathrm{p}<.001)$ as well as with their professional behavior (for Medicaid patients, residents: $\mathrm{r}=.147$, and orthodontists: $\mathrm{r}=.092, \mathrm{p}<.05$; residents: $\mathrm{r}=.360, \mathrm{p}<.001$, and orthodontists: $\mathrm{r}=.134, \mathrm{p}<.05$ ).

Finally, concerning the relationships between educational experiences and professional attitudes, the strongest correlations were found between the reported educational experiences concerning treating patients with craniofacial anomalies/developmental delays/special needs in general and attitudes toward treating patients with craniofacial anomalies and mental retardation (for craniofacial anomalies, residents: $\mathrm{r}=.500, \mathrm{p}<.001$, and orthodontists: $\mathrm{r}=.549$, $\mathrm{p}<.001)$. Again, these reported educational experiences correlated significantly with professional behavior concerning providing care for patients with craniofacial anomalies (residents: $r=.411, \mathrm{p}<.001$, and orthodontists: $\mathrm{r}=.192, \mathrm{p}<.001)$ and for patients with mental retardation/developmental disabilities (residents: $\mathrm{r}=.254, \mathrm{p}<.01$, and orthodontists: $\mathrm{r}=.127$, $\mathrm{p}<.05)$.

Table 7 offers an additional perspective on the relationship between educational experiences concerning providing care for different patient groups and professional behavior that these residents and orthodontists exhibited. In Table 7, the residents and orthodontists were divided into two categories: whether they provided care for or did not provide care for patients from diverse backgrounds, patients on Medicaid, pro bono patients, patients with craniofacial anomalies, and patients with developmental delays/developmental disabilities. For each of these five groups of patients, the residents as well as the orthodontists who provided care were more positive about their educational experiences concerning a particular patient group related to these educational experiences compared to the providers who did not treat/did not intend to treat these patients. Specifically, the residents and orthodontists who agreed that they treat patients from diverse ethnic/racial backgrounds agreed more strongly that their graduate education had prepared them well to treat patients from diverse backgrounds, on a five-point scale from $1=$ disagree strongly to $5=$ agree strongly (residents: 4.29 and orthodontists: 4.19) compared to the residents and orthodontists who said that they did not provide/intend to provide care for patients from diverse backgrounds (residents: 3.52 and orthodontists: 
3.47; $<<.001)$. Concerning patients on Medicaid, the same pattern was found. The average evaluation of educational experiences about treating patients on Medicaid of the respondents who said they did or will provide care for these patients was more positive (residents: 3.75 and orthodontists: 2.95) compared to the average evaluations of respondents who did not provide care for patients on Medicaid (residents: 3.45 and orthodontists: $2.75 ; \mathrm{p}<.042$ ). The same pattern is repeated in responses concerning providing care for pro bono cases, as well as for providing care for patients with craniofacial anomalies and mental retardation/developmental disabilities.

In summary, the survey responses from both residents and practicing orthodontists indicated that educational experiences were significantly correlated with attitudes and behavior related to providing care for patients from underserved groups.

\section{Discussion}

A number of studies have demonstrated that dental education about the treatment of patients from underserved groups has a positive effect on the professional attitudes of future providers and on their actual professional behavior. ${ }^{10-17}$ These studies also found that general dentists' attitudes and their professional behavior concerning providing care for underserved patients were significantly correlated with the degree to which they perceived that their predoctoral dental education had prepared them well to treat these patients. The objective of our study was to explore whether graduate dental education would have a similar impact on the professional attitudes and actual professional behavior of orthodontic graduate students as well as dental specialists.

Data were therefore collected from practicing orthodontists who were active members of the AAO as well as from current residents in orthodontic programs in the United States and Canada. The response rate of the orthodontic residents was almost 42 percent, which is an acceptable response rate for such a study. The fact that the 135 responding residents came from thirty-two of the sixty-nine orthodontic programs in the United States and Canada (46.4 percent) further supports the assertion that the sample might be representative of orthodontic residency programs in the United States and Canada in general. The response rate of the practicing orthodontists was almost 38 percent. A look at the background characteristics of the residents and the orthodontists supports the assumption that the respondents might be representative of their groups in regard to their demographic characteristics. The distribution of male versus female respondents in the two groups reflects the fact that increasing numbers of female residents are entering orthodontic residency programs compared to the numbers of females among the practicing orthodontists. In addition, the percentages of orthodontists and residents from different ethnic/racial backgrounds also reflected the general trend that increasing numbers of non-white residents are entering these graduate programs compared to the percentages of non-white orthodontists who graduated over the past forty years. While the majority of the orthodontists ( 88.2 percent) were from a European American background, a higher percentage of the orthodontic residents were from non-European American backgrounds, especially from Asian American (17.4 percent) and Hispanic backgrounds (5.3 percent). In addition, the age ranges of the residents (twenty-three to forty-three years) and the orthodontists (twenty-eight to seventy-five years) also correctly reflected differences between the two samples.

A first objective of this study was to assess the perceptions of the quality of classroom, clinic, and community-based graduate education devoted to preparing providers for treating patients from historically underserved patient populations. A majority of both orthodontic residents and orthodontists said they felt well prepared in their classroom-based and clinic-based education to provide care for patients from different ethnic/racial backgrounds. However, significantly smaller percentages agreed that their dental education had prepared them well to treat socioeconomically disadvantaged patients and patients with special needs. These data should raise concerns in two ways. First, if higher percentages of respondents did not feel well prepared to treat, for example, patients on Medicaid, they might be less likely to include these patient groups in their own practices once they graduate from orthodontic residency programs. Examples of how residency programs could prepare their residents for treating patients on Medicaid would be to include such information in their practice management courses, to ask residents to file Medicaid reimbursement forms on their own, and to educate them about patient-provider communication issues such as health literacy concerns. Second, not feeling well prepared to treat patients with craniofacial anomalies or other special needs could affect the providers' professional con- 
fidence when they encounter these patients in their own practices.

One limitation of this study was the fact that the educational questions did not assess the extent to which residents and orthodontists had been educated about these matters. It would have been quite interesting to collect information about the number of hours these two groups of respondents spent in community-based settings or were instructed in classroom and clinic-based settings about the treatment of these underserved patient groups.

Concerning the residents' and providers' attitudes towards providing care for these patient groups, the data showed clearly that while the respondents had positive attitudes towards providing care for patients from diverse ethnic/racial backgrounds - mirroring the high levels of agreement with the statement that their education had prepared them well to treat these patients - the residents were less likely to report that they were confident when treating patients with craniofacial anomalies or developmental delays. While the difference in the confidence levels of practicing orthodontists and residents might be due to the fact that orthodontists were likely to have had more experiences treating these patients, the residents' low level of confidence should raise concerns about the quality of orthodontic programs in regard to training graduates to provide care for anatomically or mentally challenged patients. Concerning the respondents' attitudes, it is interesting to note that while there was no difference between the two groups of respondents concerning their attitudes towards patients from different ethnic/racial groups, the residents' attitudes towards providing care for patients on Medicaid and pro bono cases as well as their attitudes towards treating patients with different special needs were significantly more positive than the orthodontists' attitudes. These differences in values might reflect changes in society at large that show that younger cohorts in the United States tend to be more supportive of postmaterialistic values such as protecting the environment than older cohorts, ${ }^{19}$ while older cohorts might endorse materialistic values more strongly than younger cohorts. In any case, it would be interesting for a panel study to assess whether these attitudes change once the residents begin their professional practice.

The data concerning professional behavior showed that high percentages of orthodontists reported that they treat patients from underserved groups - with the exception of patients on Medicaid. The responses of the residents mirrored the pattern of the orthodontists' responses, with the highest percentage of residents indicating that they will provide orthodontic treatment for patients from diverse ethnic/racial groups and the lowest percentage indicating that they would treat patients on Medicaid. However, their percentages were significantly lower in regard to treating pro bono cases, patients with craniofacial anomalies, and patients with mental retardation compared to the percentages of practicing orthodontists. This situation, especially the low percentages of respondents who treated/intended to treat patients on Medicaid, should alert dental educators who are committed to reducing access to care problems for underserved patients.

The central question of this study was whether there is a relationship between the quality of graduate dental education about providing care for underserved patient groups and professional attitudes and especially professional behavior of the graduates. Our findings indicate that such a relationship exists. The better the respondents felt prepared to provide care for a particular underserved group of patients, the better were their attitudes towards these patients and the more likely they were to provide care for them. These findings mirror the results of studies concerning the relationship between predoctoral education about treating patients from underserved groups and the attitudes and behaviors of general dentists. Dental educators have to be aware that dental education shapes the future professional behavior of their students and can thus contribute to reducing oral health disparities and to increasing access to dental care for underserved groups of patients.

While this study focused on one particular dental specialty, orthodontics, research should explore this question in other dental specialties as well. Does dental education affect endodontists', prosthodontists', and periodontists' attitudes towards providing care for underserved patients? An answer to these questions could provide further support that there is a relationship between graduate dental education and the access to care problems in the United States. Such findings could challenge graduate dental program faculty and administrators alike to reflect on their own programs and the degree to which their programs contribute to reducing access to care problems.

\section{Conclusions}

Based on these findings, several conclusions can be drawn. First, residents and orthodontists 
largely agreed that their classroom and clinic-based graduate dental education prepared them well to treat patients from diverse ethnic/racial groups. However, residents and practicing orthodontists indicated they were less well prepared to treat socioeconomically disadvantaged patients and patients with different special needs. Second, a comparison of the responses of the residents and the orthodontists showed that the residents rated their educational experiences more positively than the orthodontists did. Third, residents reported a relatively low level of confidence concerning providing care for patients with craniofacial anomalies and developmental delays. This finding should challenge dental educators to reflect on the quality of education they provide in their programs. Fourth, orthodontists' actual behavior concerning the treatment for patients from these underserved groups was significantly higher than the residents' behavioral intentions. Increasing residents' willingness to contribute to reducing the access to care problems in the United States has to become a priority. Finally, and most importantly, a relationship was found between the quality of dental education in this context and the professional attitudes and behavioral indicators of the respondents. Faculty members and administrators in orthodontic graduate programs should realize the important contributions these educational experiences can make to increasing access to care for underserved patient populations.

\section{Acknowledgments}

We thank the Delta Dental Foundation in Michigan for a grant to the first author to support this study. We thank the American Association of Orthodontists (AAO) for providing us with the names and addresses of their active members and the organizers of the 2007 meeting of the Graduate Orthodontic Residents Program for allowing us to hand out surveys to the attending orthodontic residents. We thank Dean Peter Polverini of the University of Michigan School of Dentistry for his support for this research by sending a recruitment letter to $\mathrm{AAO}$ members.

\section{REFERENCES}

1. Oral health in America: a report of the surgeon general. NIH Publication 00-4713. Rockville, MD: U.S. Department of Health and Human Services, National Institute of Dental and Craniofacial Research, National Institutes of Health, 2000:7.

2. Hunt O, Hepper P, Johnston C, Stevenson M, Burden D. Professional perceptions of the benefits of orthodontic treatment. Eur J Orthod 2001;23:315-23.
3. Christopherson EA, Briskie D, Inglehart MR. Objective, subjective, and self-assessment of preadolescent orthodontic treatment need: a function of age, gender, and ethnic/racial background? J Public Health Dent, in press.

4. Christopherson EA, Briskie D, Inglehart MR. Preadolescent orthodontic treatment need: objective and subjective provider assessments and patient self-reports. Am J Orthod Dentofacial Orthop, in press.

5. National Health and Nutrition Examination Survey III, 1988-94. Hyattsville, MD: U.S. Department of Health and Human Services, Centers for Disease Control and Prevention, National Center for Health Statistics, 1998:1 [computer laser optical disc].

6. Proffit WR, Fields HW Jr, Moray LJ. Prevalence of malocclusion and orthodontic treatment need in the United States: estimates from the NHANES III survey. Int J Adult Orthod Orthognathic Surg 1998;13(2):97-106.

7. Shaw WC. The influence of children's dentofacial appearance on their social attractiveness as judged by peers and lay adults. Am J Orthod 1981;79(4):399-415.

8. Helm S, Kreiborg S, Solow B. Psychosocial implications of malocclusion: a 15-year follow-up study in 30-year-old Danes. Am J Orthod 1985;87(2):110-8.

9. Klages U, Bruckner A, Zentner A. Dental aesthetics, selfawareness, and oral health-related quality of life in young adults. Eur J Orthod 2004;26(5):507-14.

10. Noonan AS, Evans CA. The need for diversity in the health professions. J Dent Educ 2003;67(9):1030-3.

11. Terrell C, Beaudreau J. 3000 by 2000 and beyond: next steps for promoting diversity in the health professions. J Dent Educ 2003;67(9):1048-52.

12. Novak KF, Whitehead AW, Close JM, Kaplan AL. Students' perceived importance of diversity exposure and training in dental education. J Dent Educ 2004;68(3):355-60.

13. Dao LP, Zwetchkenbaum S, Inglehart MR. General dentists and special needs patients: does dental education matter? J Dent Educ 2005;69(10):1107-15.

14. Smith CS, Ester TV, Inglehart MR. Dental education and care for underserved patients: an analysis of students' intentions and alumni behavior. J Dent Educ 2006;70(4):398-408.

15. Rich JP III, Straffon L, Inglehart MR. General dentists and pediatric dental patients: the role of dental education. J Dent Educ 2006;70(12):1308-15.

16. Burtner AP, Dicks JL. Providing oral health care to individuals with severe disabilities residing in the community: alternative care delivery systems. Spec Care Dentist 1994;14(5):188-93.

17. Mofidi M, Konrad TR, Porterfield DS, Niska R, Wells B. Provision of care to the underserved populations by National Health Service Corps alumni dentists. J Public Health Dent 2002;62(2):102-8.

18. Ajzen I, Fishbein M. Attitudes: their structure, function, and consequences. New York: Psychology Press, 2008:425-43.

19. Inglehart R. Modernization and postmodernization: cultural, economic, and political change in 43 societies. Princeton: Princeton University Press, 1997. 